\title{
Loanwords stress and intonation in Algerian Arabic
}

Ismaël Benali

CLILLAC-ARP, Université Paris Diderot, France

https://doi.org/10.36505/ExLing-2017/08/0004/000306

\begin{abstract}
This paper deals with stress and intonation patterns of loanwords in Algerian Arabic and in particular in Algiers and Oran dialects. It shows that speakers always transferred the stress pattern of Algerian Arabic in borrowed words: the final syllable is stressed if it is the only heavy syllable in the word or if it is superheavy, otherwise stress is on the penultimate syllable. Intonation patterns are also transferred to loanwords in focus and polar questions. Focus is characterized in the Algiers dialect by a falling melodic contour occurring on the last syllable. In the Oran dialect, intonation is realized with a flat or slightly rising contour. In polar question Algiers speakers produce a rising-falling contour whereas the Oran speakers produce a rising melodic contour on the last syllable.
\end{abstract}

Key words: loanword, Algerian Arabic, stress, focus, polar question

\section{Introduction}

The Algerian Arabic originates from the North African Arabic and is spoken by more than $70 \%$ of the population. It is the main vehicular language of the country. The Algiers variety is spoken in the capital in the Center of Algeria. The Oran variety is spoken in the city of Oran in the West of Algeria. In previous studies (Benali, 2008, Benali, 2016), it appeared that Algerian dialects can be identified by prosodic cues. I found also that intonation patterns which characterize Algiers and Oran varieties are marked more clearly in focus and polar question.

These two varieties have great number of borrowed words from French whereas the Oran dialect contains also Spanish loanwords. These loanwords are phonetically and morphologically modified (Gallicism) and adapted to the speakers mother tongue (Arabic or Berber) as in [si.'ni.ma] from the French word "cinéma" and in [bo.'ga.do] from the Spanish word "abogado".

In this research, I examine the place of the stress of loanwords and their prosodic realization in focus and polar question.

Few studies on stress were carried out on Algerian Arabic. Aït Oumaziane Ramadane studied the stress in the Arabic dialect of Constantine (Ait Oumeziane, 1981), Farouk Bouhadiba in the Oran dialect (Bouhadiba, 1988) and Aziza Boucherit in Algiers Arabic (Boucherit, 2006). From our study (Benali, 2015) stress falls on the final syllable if it is the only heavy syllable in the word $(\mathrm{V}$ : or $\mathrm{VC})$, or if it is superheavy $\mathrm{V}: \mathrm{C}(\mathrm{C})$

ExLing 2017: Proceedings of 8th Tutorial and Research Workshop on Experimental Linguistics, 19-22 June, Heraklion, Crete, Greece 
or VCC. Otherwise the penultimate syllable is stressed.

Few studies have dealt with the integration of loanwords into dialectal Arabic at the prosodic level. Borrowed words from French tends to lose their " tonic" accent to submit to the accentual rules of the Tunisian dialectal Arabic (Mzoughi, 2015). Naïma Fadil-Barillot presented three types of the intonative contours in the code-switching of Morroccan Arabic and French : the intonation of matrix language, the composed intonation and the recomposed intonation (Barillot, 2002).

\section{Methodology}

Recordings for this study were made in Algiers and Oran. 20 Algiers speakers and 20 Oran speakers were recorded in a quiet room using a lapel microphone. Speakers were between 22 and 30 years old. The majority of them were students and have lived all their childhood and adolescence in their respective cities.

The corpus is composed of spontaneous and read speech. The spontaneous speech utterances were extracted from a conversation between speakers and the experimenter (who was speaking a southern variety). Borrowed words and code switching were observed in this corpus.

Acoustic analysis were carried on the speech analysis/resynthesis program 'WinPitch' (Martin, 2000).

\section{Analysis}

\section{Stress in spontaneous speech}

The use of the loanword "ball" in our corpus illustrates the difference between the two dialects: Algiers speakers use the French word "ballon" and Oran speakers use the Spanish one "bola". In both cases stress is on the penultimate: ['ba.ló], ['bo.la].

Overall, Oran speakers stress the penultimate syllable as in ['sba.na] "Spain" and the final syllable when heavy and closed: [sba.'no:l] "Spanish". In the word Cervantes the stress is not on the penultimate as in Spanish but in the last syllable.

The following example shows how the loanword is morphologically integrated: ['kunt 'ntri.ni u ha.'bəst] "I trained and then I stopped" ['ntri.ni] from the French verb "entraîner", [n] and [i] are Arabic morphological marks. Stressed syllable is longer and has a rising F0.

Algiers speakers stress also the penultimate syllable as in [teks.'plo.zi] "you explode (in anger)" from the French verb "exploser". This syllable is lengthened whereas the finale syllable carries a falling F0 as in ['dza.zət 
in.'ti:k] "It went very well" from the French word "antique" in the meaning of well, good.

So Algiers and Oran speakers in loanwords stress the final syllable if it is the only heavy syllable in the word or if it is superheavy. In the other case the penultimate is stressed. Acoustic analysis shows that Algiers speakers used more F0 range to stress the syllable than the Oran speakers $(\mathrm{p}<0,0001)$ who use more vowel lengthening $(\mathrm{p}<0,0013)$.

\section{Intonation in read speech}

In the statement used for this study ['Jra kat.sã.' kat 'ba.fi] "He bought a 404 pickup", there are two loanwords [kat.sã.'kat] from the French model car "404 Peugeot" and ['ba.ji] from the French word "bachée" meaning a pickup. Only the second word is stressed on the penultimate syllable, forming an accent group. The speakers were asked to produce this statement with an emphatic focus on the last word and to produce it as a polar question.

Emphatic narrow focus is produced in the Algiers dialect by a rising contour on the stressed syllable followed by a falling contour. In the Oran dialect, this focus is realized with a flat or slightly rising contour on the stressed syllable (figure 1). In both dialects the stressed syllable is lengthened.

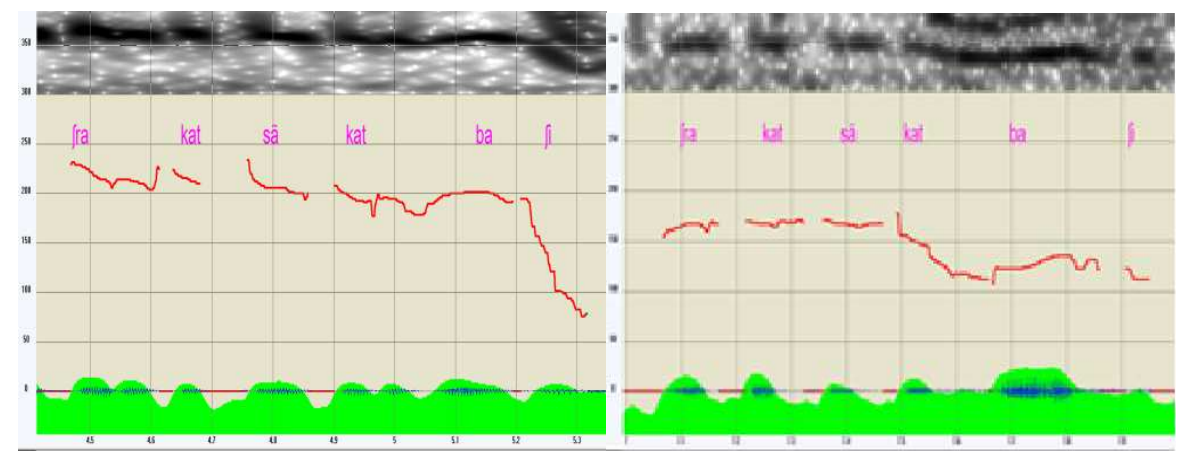

Figure 1. Emphatic narrow focus produced by Algiers (left) and Oran speakers (right).

In polar question Algiers speakers produced an amplified rising-falling contour while Oran speakers produced on the last syllable a rising contour (figure 2). 


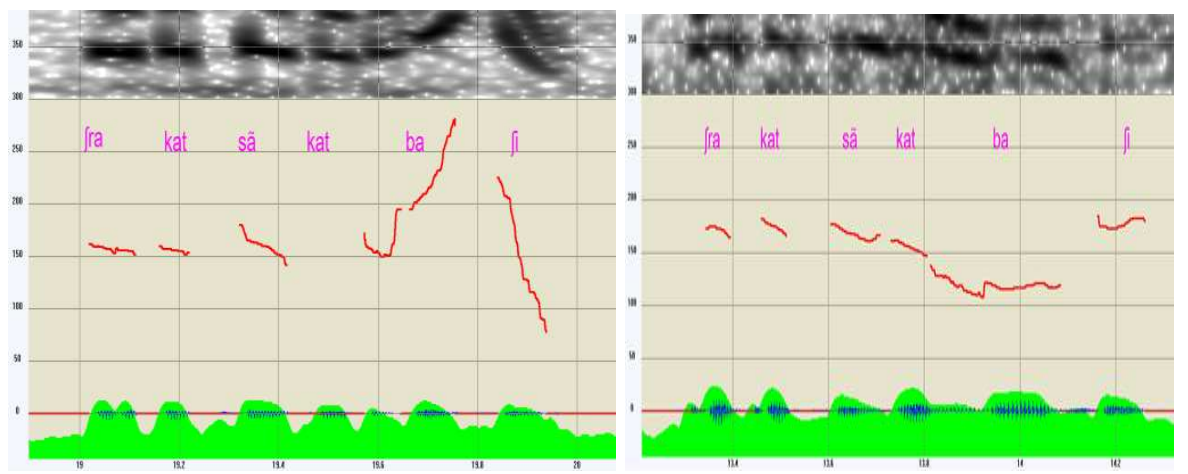

Figure 2 Polar question produced by Algiers (left) and Oran speakers (right).

These results are similar to those obtained in Algiers and Oran dialectal Arabic.

\section{Conclusion}

The results of this study show that Algerian speakers always transferred the stress pattern of Algerian Arabic to loanwords words. Intonation patterns are also transferred in focus and polar questions.

\section{References}

Aït Oumeziane, R. 1981. Le Parler Arabe de Constantine. Doctorat, Université Sorbonne Nouvelle Paris 3.

Barillot, N.F. 2002. Etude sociolinguistique et intonative de l'alternance codique arabe marocain français.

Benali, I. 2008. La question totale dans les parlers algérois et oranais. Language design: journal of theoretical and experimental linguistics, 0039-46.

Benali, I. 2015. La focalisation dans les parlers algérois et oranais: étude prosodique. Sorbonne Paris Cité.

Benali, I. 2016. The identification of two Algerian Arabic dialects by prosodic focus. ExLing 2016, 37.

Boucherit, A. 2006. Algiers Arabic. Encyclopedia of Arabic Language and Linguistics, 58-66.

Bouhadiba, F.A.N. 1988. Aspects of Algerian Arabic verb phonology and morphology. University of Reading.

Martin, Ph. WinPitch 2000: a tool for experimental phonology and intonation research. Proceedings of the Prosody 2000 Workshop, 2000.

Mzoughi, I. 2015. Intégration des emprunts lexicaux au français en arabe dialectal tunisien. Université de Cergy Pontoise. 